\title{
Structure and Rheological Behaviour of Agar Extracted From Madagascar Sea Coast Algae
}

\author{
Marie Pascaline Rahelivao ${ }^{1}$, Hanta Andriamanantoanina ${ }^{1, *}$, Alain Heyraud ${ }^{2}$ and Marguerite \\ Rinaudo $^{2, \ddagger}$ \\ ${ }^{1}$ Centre National de Recherche sur l'Environnement (CNRE), BP 1739 Fiadanana, 101 Antananarivo, Madagascar \\ ${ }^{2}$ Centre de Recherches sur les Macromolécules Végétales (CERMAV-CNRS) affiliated with Joseph Fourier University, \\ BP53, 38041 Grenoble cedex 9 France \\ Present address: Biomaterials Applications, 6, rue Lesdiguières, 38000 Grenoble France
}

\begin{abstract}
Polysaccharide from an original red algae (Gelidium sp) was extracted with hot water, clarified, and precipitated in presence of ethanol. NMR spectroscopic analyses and chromatographic separation after complete hydrolysis showed that this polysaccharide was composed predominantly of a repeating-unit based on 4- $O$-3,6-anhydro- $\alpha$-L-galactopyranose and 3-O- $\beta$-D-galactopyranose confirming their agar nature. The Gelidium sp agar (representing $16 \mathrm{w} \%$ on the basis of dried crude algae) has a regular chemical structure and forms strong gels in aqueous medium. Its rheological behavior is examined as a function of polymer concentration and temperature.
\end{abstract}

Keywords: Red algae, Agarose, Hydrolysis, Gelation, ${ }^{1} \mathrm{H}$ NMR, Rheology.

\section{INTRODUCTION}

Agar consists of a series of polysaccharides extracted from Rhodophyta seaweeds (red algae). They are currently used for many biological and industrial applications [1-3] having also an important role in various areas of emerging biotechnology [4]. Usually, the neutral fraction named agarose, being soluble in boiling water but insoluble in cold water, is extracted with water at high temperature. Agars are commercially important due to their gel-forming properties. It is generally agreed that the basic repeat unit of this polysaccharide is agarobiose which consists of 4-O-3,6anhydro- $\alpha$-L-galactopyranose (A unit) and $3-O-\beta$-Dgalactopyranose (B unit) [5]. Variable amounts of substituent groups are present along the polysaccharide chains in the different fractions of agar, the most frequent substituents being methoxyl, sulphate esters and pyruvate ketal groups [6]. Sulphate groups are located at C-4 of D-galactose units (B unit) and C-6 of L-galactose units (A unit), methoxyl groups are located at C-6 of D-galactose (B unit) and C-2 of L-galactose residues (A unit) [7]. Moreover, L-galactose-6sulphate residues are often present as a partial replacement of 3, 6-anhydro-L-galactose [8-12]. Many red algae contain more complex galactans devoid of gelling ability. In addition, several red algae may contain sulphated mannans or neutral xylans instead of sulphated galactans as the main structural polysaccharides [13].

\footnotetext{
*Address correspondence to this author at the Centre National de Recherche sur l'Environnement (CNRE), BP 1739 Fiadanana, 101 Antananarivo, Madagascar; Tel: +261 3312397 12;

E-mail: andriamanantoanina@yahoo.fr
}

The gel-forming properties of agar are directly related to the presence of the 3,6-anhydro-L-galactopyranose residues due to the three equatorial hydrogen atoms and cycle constrains allowing the molecule to form a double helix [14]. The association of the double helices is the basis of the thermoreversible gel formed with agarose and also $\kappa-$ and 1 carrageenans extracted from red algae [15]. The ability to form gels is widely influenced by the chemical substituents $[16,17]$ as well as by the molar mass and molar mass distribution of the agar polymers [18]. The conformational analysis of agarose (pure $\mathrm{AB}$ copolymer) also predicts single and double helices $[19,20]$. The purpose of the present work is to determine the chemical structure and rheological properties of agar extracted from an original species of red algae isolated from the Madagascar coast.

\section{EXPERIMENTAL}

\subsection{Materials}

The agar investigated was extracted from a red algae (Gelidium sp, named RHT) collected from Fenerive-Est, in east coasts of Madagascar; the corresponding strain is not yet completely identified. After collection, specimens were washed under tap water, cleaned by hands to get out of epiphytes and other impurities, dried in a Binder Drying oven (R3, type FD 53 Germany) at $50{ }^{\circ} \mathrm{C}$ for 1 day and ground in a ultraturrax Janke- Kunkel type MFC, IKA (Germany), stitch $1 \mathrm{~mm}$.

Myo-inositol with a purity better than $99.5 \%$ was provided by Fluka, dimethylsulfoxide (DMSO) with a purity of $99.9 \%$ and sodium borohydride $>96 \%\left(\mathrm{NaBH}_{4}\right)$ by SigmaAldrich. $\mathrm{HCl} 37 \%, \mathrm{SO}_{4} \mathrm{H}_{2} 96 \%$, ethanol $96.2 \%$ and 
methanol are from Carlo Erba. $\mathrm{D}_{2} \mathrm{O}$ was purchased from Eurisotop (France).

\subsection{METHODS}

\subsubsection{Extraction}

3 grams of dried crushed seaweed were stirred in distilled water on a Fisherbrand magnetic stirrer hot plate, model L81 and placed in water bath JP Selecta s.a.(Spain) at $100{ }^{\circ} \mathrm{C}$ under reflux for 2 hours. The hot mixture was filtered immediately on Whatman filter papers (1,2 3, diameter $110 \mathrm{~mm}$ ) at high temperature to prevent clogging; the filtrate was added, at room temperature, with an equal volume of distilled EtOH $\left(90^{\circ}\right)$ and let overnight at $4{ }^{\circ} \mathrm{C}$ in a refrigerator/freezer (Sharp, 431L) to allow complete precipitation. The precipitate obtained was washed with ethanol, and dried in a Binder Drying oven (R3, type FD 53, Germany) at $50{ }^{\circ} \mathrm{C}$ for 1 day. Gelidium sp extracted and purified polysaccharides represented $16 \%$ on the basis of dried ground algae. The polymer extracted was named "agar" in the following because it may contain chains with different substituents.

\subsubsection{Elemental Analysis}

Elemental analysis used to determine the nitrogen, carbon and sulphur contents was realized by the 'Service Central d'Analyse' from CNRS (Solaize, France). Sulphur content was related with the presence of sulphate substituents and nitrogen to the presence of proteins.

\subsubsection{Gas Chromatography}

The polysaccharide was hydrolysed with $2 \mathrm{M} \mathrm{H}_{2} \mathrm{SO}_{4}$ for $4 \mathrm{~h}$ at $100{ }^{\circ} \mathrm{C}$ in the presence of inositol as internal standard. The hydrolysate was neutralized with barium carbonate, deionized and the sugars were then reduced with an excess of $\mathrm{NaBH}_{4}$ for $16 \mathrm{~h}$ at room temperature. Borate compounds were eliminated by $\mathrm{MeOH} / \mathrm{HCl} 1 \% \mathrm{v} / \mathrm{v}$ treatment. The reduced sample was acetylated with acetic anhydride/pyridine (v/v) at $100{ }^{\circ} \mathrm{C}$ for $1 \mathrm{~h}$. After cooling and dilution with water, the mixture was evaporated to dryness. At end, the alditol acetate derivatives prepared were analyzed by gas chromatography equipped with a flameionisation detector (CPG/ FID) on a SP2380 macrobore column $(0.53 \mathrm{~mm}$ x $30 \mathrm{~m})$ in a Hewlett Packard 5890A system using various alditol acetate carbohydrates as standards. The carrier gas was high-purity nitrogen and the injector port was heated at $250{ }^{\circ} \mathrm{C}$. For sample separation the following conditions were applied: $4 \mathrm{~min}$ at an initial temperature of $195{ }^{\circ} \mathrm{C}$ followed by an incremental increase $\left(2.5^{\circ} \mathrm{C} / \mathrm{min}\right)$ to a final temperature of $225^{\circ} \mathrm{C}$ during $2 \mathrm{~min}$.

\subsubsection{NMR Spectroscopy}

${ }^{1} \mathrm{H}$ NMR spectra of extracted polysaccharide was recorded at $85{ }^{\circ} \mathrm{C}$ on $10 \mathrm{mg} / \mathrm{ml}$ solution in $\mathrm{D}_{2} \mathrm{O}$. These experiments were performed using a Bruker Avance 400 spectrometer operating at $400.13 \mathrm{MHz} .{ }^{1} \mathrm{H}$ chemical shifts were measured in parts per million, at $85{ }^{\circ} \mathrm{C}$ and the chemical shifts were referred to tetramethylsilane (TMS). Firstly, the methoxyl and pyruvic acid ketal contents were quantified. Then, ${ }^{1} \mathrm{H}$ NMR spectrum of Gelidium sp agar was performed at different temperatures from 30 to $85{ }^{\circ} \mathrm{C}$ to evidence possible change in polysaccharide conformation.

\subsubsection{Gel Characterization}

Gels were casted from a heated aqueous solution of the total agar extracted from Gelidium sp (10 g/L) into cylindric cuvets. Cylindric pieces of gel with a $2.4 \mathrm{~cm}$ diameter and a thickness varying between 2 and $5 \mathrm{~mm}$ were recovered after cooling. Rheological properties of gels were obtained with a TA Instruments rheometer (AR2000) by dynamic measurements with parallel plates geometry giving the evolution of dynamic moduli ( $\mathrm{G}^{\prime}$, the storage modulus and G', the loss modulus) as a function of the frequency in the linear domain. A Peltier plate allowed varying the temperature (temperature ramp $5 \% \mathrm{~min}$ ) to determine the melting/gelling temperatures of agar gels. At low agar content, a cone-plate geometry was used with a $4 \mathrm{~cm}$ diameter and $3.59^{\circ}$ angle cone.

\section{RESULTS AND DISCUSSION}

It seems particularly important to establish the details of the chemical structure of the crude extract from Gelidium $\mathrm{sp}$ forming easily strong gels in aqueous medium.

\subsection{NMR Spectroscopy}

NMR spectroscopy of the initial polymer confirmed that agarobiose was the main repeating unit in the polysaccharides extracted from Gelidium $\mathrm{sp}[13,21]$ (Fig. 1). The signal at $1.52 \mathrm{ppm}$ in the ${ }^{1} \mathrm{H}$ NMR spectra was assigned to the methyl group of pyruvic acid ketal linked to the 4- and 6- positions of $\beta$-D-galactopyranose residues [22]. Moreover, the small signal at $5.29 \mathrm{ppm}$ was attributed to the anomeric proton of the L-galactopyranose residue, being deshielded by the adjacent pyruvate substituent. The signals appearing at 3.48 and $3.52 \mathrm{ppm}$ were assigned to the methoxy groups of 6-O-methyl-D-galactose and 2-O-methyl3,6-anhydro-L-galactose respectively [23].

At end, ${ }^{1} \mathrm{H}$ NMR of the Gelidium sp agar was studied as a function of temperature to evidence a possible conformational change (spectra not shown); it is known that, in the helical conformation, the signals are very broad and develop when temperature increases in relation with the conformational change to coil. The spectra obtained in the presence of a small amount of DMSO taken as reference clearly indicated, as reflected by the agar signals amplitude increases, that the mobility of the polysaccharide increased when temperature increased corresponding to progressive melting of the aggregates of double helices evidenced by optical rotation and DSC [24]. These results are discussed later in relation with the gel properties.

\subsection{Chemical Composition of Crude Extracts.}

Elemental analysis on the agar sample allows determining the carbon $(\mathrm{C})$, nitrogen $(\mathrm{N})$ and sulphur $(\mathrm{S})$ percentages to test the purity of the samples and elements of global composition. Data are given in Table $\mathbf{1}$. 


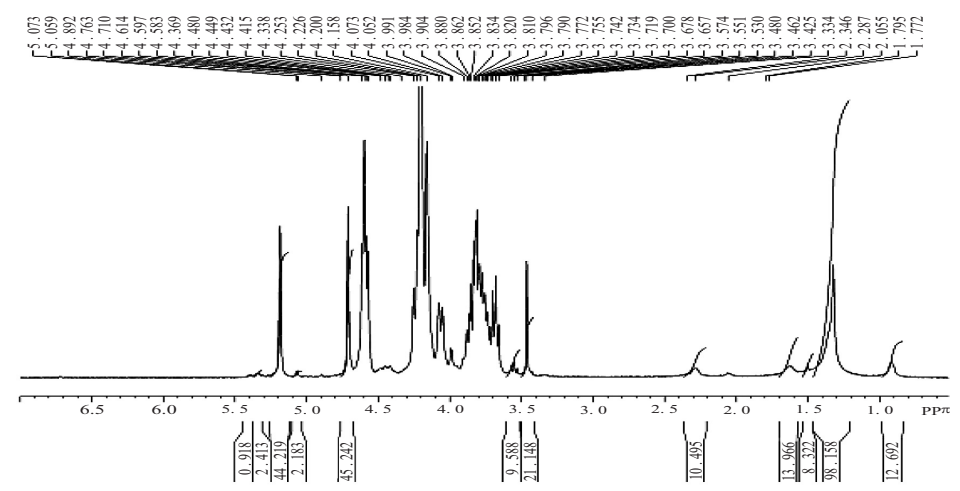

Fig. (1). ${ }^{1} \mathrm{H}$ NMR of Gelidium $\mathrm{sp}(\mathrm{RHT})$ agar in $\mathrm{D}_{2} \mathrm{O}$ at $85^{\circ} \mathrm{C}$.

Table 1. Elemental Analysis on the RHT Agar Sample

\begin{tabular}{|c|c|}
\hline Element Determined in w\% & Gelidium $\mathbf{s p}$ \\
\hline \hline C & 37.4 \\
\hline N & $<0.3$ \\
\hline S & 0.55 \\
\hline
\end{tabular}

The estimation based on the dimeric repeat unit of pure agarose should give $\mathrm{C} \%=42.5$ in relatively good agreement with the value found; the very low yield in nitrogen signified that there was negligible amount or no protein. The sulphur content allowed to evidence the low content of sulphate ($\left.\mathrm{SO}_{3} \mathrm{H}\right)$ substituents. Then, after analysis of hydrolysed polysaccharides with $\mathrm{H}_{2} \mathrm{SO}_{4}$ by gas chromatography of the alditol acetates, the monosaccharide composition was obtained (Table 2).

Table 2. Composition of Gelidium sp Agar by Gas Chromatography

\begin{tabular}{|c|c|}
\hline Sugar Units (w \%) & Gelidium $\mathbf{s p}$ \\
\hline \hline galactose & 82.3 \\
\hline glucose & 2.5 \\
\hline 6-O-Me-Gal & 15.1 \\
\hline 2-0-Me-Gal & $\sim 0$ \\
\hline
\end{tabular}

The presence of a low content of glucose in the crude extract seems to be related to some contamination.

\subsection{Characterization of the Gel}

The initial Gelidium sp agar formed gel in aqueous medium; it was investigated in the following. $0.1 \mathrm{M} \mathrm{KCl}$ solution was used as solvent to prepare gels for screening possible electrostatic repulsions which should be due to the presence of few sulphates in the total extract, as evidenced by sulphur titration (see Table $\mathbf{1}$ ).

\subsubsection{Influence of Polymer Concentration}

The influence of polymer concentration (from 1 to 15 $\mathrm{g} / \mathrm{L}$ ) was studied to determine the critical concentration for gel formation. The experimental data are given in Table 3.

At $25{ }^{\circ} \mathrm{C}$, the $1 \mathrm{~g} / \mathrm{L}$ system remained a solution with macrogels $\left(G^{\prime}\right.$ and $G$ ' were nearly superimposed indicating the limit for gelation and they were increasing with frequency), but at $3 \mathrm{~g} / \mathrm{L}$, a very soft gel was obtained; both samples were tested with a cone-plate geometry. The higher concentrations gave strong gels (tested with a plate-plate geometry) for which, the moduli increased rapidly with polymer concentration. The rheological behaviour in $0.1 \mathrm{M}$ $\mathrm{KCl}$ is given in Fig. (2).

At polymer concentration $\mathrm{C} \geq 3 \mathrm{~g} / \mathrm{L}$, a dependence of $\mathrm{G}^{\prime}$ moduli with the frequency (of the order of $G^{\prime} \sim C^{2}$ ) was observed as previously found for $\kappa$-carrageenan and gellan [25]. Between 1 and $3 \mathrm{~g} / \mathrm{L}$, a change in the behaviour was evidenced: at $1 \mathrm{~g} / \mathrm{L}, \mathrm{G}^{\prime}<\mathrm{G}^{\prime}$, at $25^{\circ} \mathrm{C}$ but at $3 \mathrm{~g} / \mathrm{L}, \mathrm{G}^{\prime}>\mathrm{G}^{\prime}$ '. For this specific agar extract, we deduced a critical concentration for gelation located around $\mathrm{c} \sim 2 \mathrm{~g} / \mathrm{L}$ in $0.1 \mathrm{M}$ $\mathrm{KCl}$ at $25^{\circ} \mathrm{C}$.

\subsubsection{Influence of the Temperature}

The temperature increase was imposed up to $85^{\circ} \mathrm{C}$. The evolution of $G^{\prime}$ moduli are given for different polymer concentrations in Fig. (3) allowing to determine the melting temperature for the gels. For $1 \mathrm{~g} / \mathrm{L}$, the value were extremely low with no significant dependence on temperature and no uniform gelation. At $3 \mathrm{~g} / \mathrm{L}$, the gel moduli decreased when temperature increased over $45{ }^{\circ} \mathrm{C}$. Larger effect was observed at $10 \mathrm{~g} / \mathrm{L}$ : G' was much larger than $\mathrm{G}$ ', (as shown in Fig. 2) at low temperature and decreases strongly over 50 ${ }^{\circ} \mathrm{C}$; a crossover of $\mathrm{G}$ ' and $\mathrm{G}$ ', was obtained at $83{ }^{\circ} \mathrm{C}$ corresponding to the melting of the gel (data not shown for clarity of the figure). On the same sample, on temperature decrease, $G^{\prime}$ started to increase around $50{ }^{\circ} \mathrm{C}$ (the $\mathrm{G}^{\prime}, \mathrm{G}$ ' 'crossover was located at $55^{\circ} \mathrm{C}$ ) corresponding to the progressive gelling of this polymer. The large hysteresis observed for a temperature cycle characterized this agar sample indicating a large degree of regularity in the chemical structure. From these data, it was also shown that the melting temperature increased when polymer concentration 


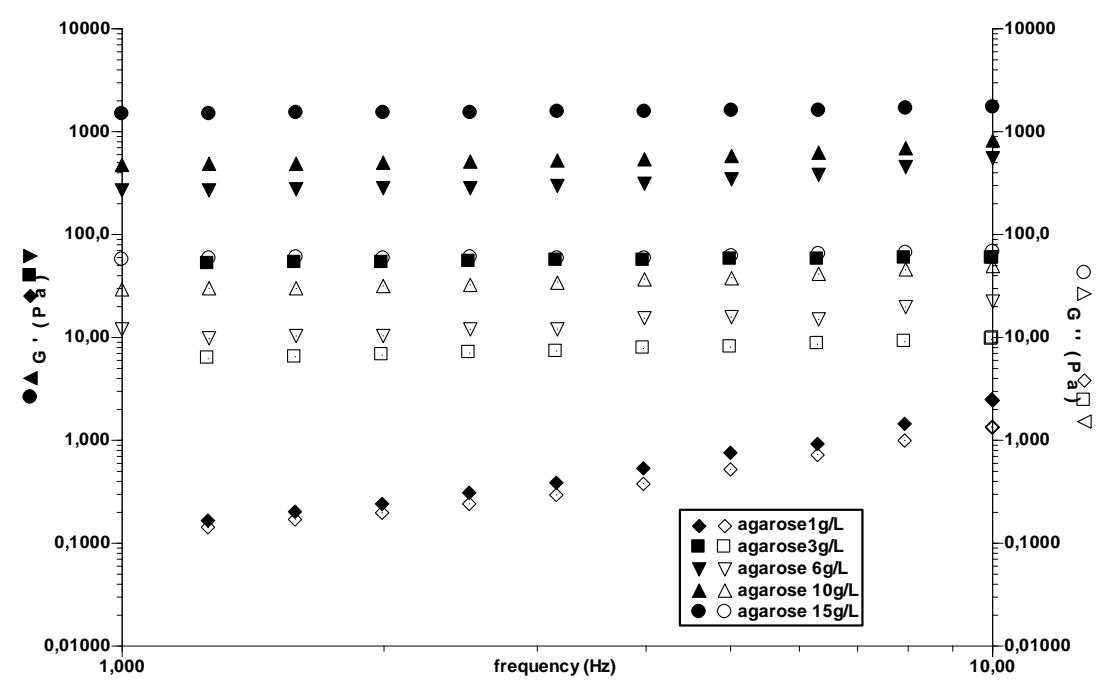

Fig. (2). Influence of polymer concentration on the gel moduli (G' filled symbols; G',open symbols) at $25{ }^{\circ} \mathrm{C}$ in $0.1 \mathrm{M} \mathrm{KCl}$.

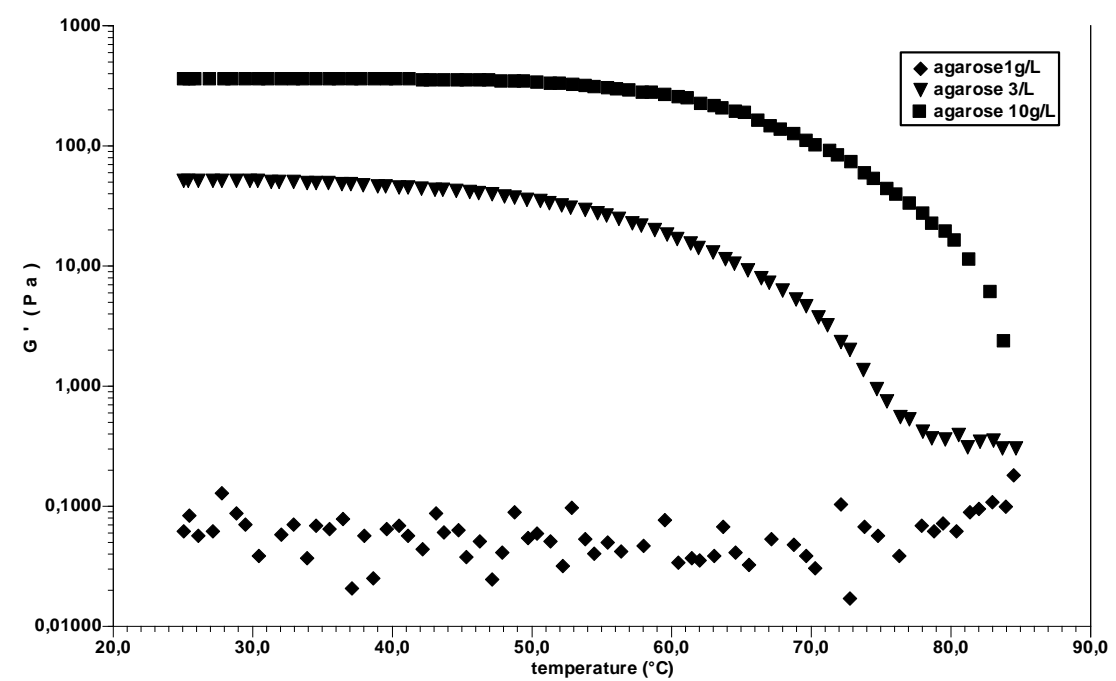

Fig. (3). Influence of temperature increase on the G' modulus measured at $1 \mathrm{~Hz}$ for agar at different concentrations.

Table 3. Rheological Characteristics of Gelidium sp Agar Gels Formed in Aqueous Solutions at Different Polymer Concentrations and Tested at Different Temperatures

\begin{tabular}{|c|c|c|c|}
\hline $\mathbf{C}(\mathbf{g} / \mathbf{L}) /$ Temperature & $\begin{array}{c}\text { G'(Pa) } \\
\text { at } \mathbf{1 H z}\end{array}$ & $\begin{array}{c}\text { G'’(Pa) } \\
\text { at } \mathbf{1 H z}\end{array}$ & $\begin{array}{c}\text { G'/G' } \\
\text { at } \mathbf{1 ~ H z})\end{array}$ \\
\hline \hline 1 at $25^{\circ} \mathrm{C}$ & 0.146 & 0.124 & 1.2 \\
\hline 3 at $25^{\circ} \mathrm{C}$ & 50.52 & 6.03 & 8.4 \\
\hline 3 at $85^{\circ} \mathrm{C}$ & 0.30 & 0.23 & 20.8 \\
\hline 6 at $25^{\circ} \mathrm{C}$ & 446.5 & 21.5 & 27 \\
\hline 10 at $25^{\circ} \mathrm{C}$ & 639.5 & 23.7 & 1.9 \\
\hline 10 at $85^{\circ} \mathrm{C}$ & 0.70 & 55.9 & -2 \\
\hline 15 at $25^{\circ} \mathrm{C}$ & 1464 & 26.2 \\
\hline
\end{tabular}

increased: located around $77{ }^{\circ} \mathrm{C}$ at $3 \mathrm{~g} / \mathrm{L}$, it shifted to $83{ }^{\circ} \mathrm{C}$ at $10 \mathrm{~g} / \mathrm{L}$ where $\mathrm{G}^{\prime}=\mathrm{G}^{\prime}$ '. The high temperature of melting was in agreement with the chemical composition of Gelidium sp agar containing a low yield in substituent.
Considering the evolution of the NMR spectra with temperature, it was clear that the decrease in $\mathrm{G}^{\prime}(\mathrm{Pa})$ down to melting was related to the increase of the $\mathrm{H}-1$ signal for galactose unit relative to DMSO (at $2.8 \mathrm{ppm}$ ) used as reference.Temperature increased progessively the mobility 
Table 4. Influence of the Temperature on the Storage Modulus (G') and NMR Mobility

\begin{tabular}{|c|c|c|}
\hline Temperature $\left({ }^{\circ} \mathbf{C}\right)$ & G' $($ Pa) & Gal/DMSO Relative NMR Signal Area \\
\hline \hline 25 & 356.7 & 0.74 \\
\hline 45 & 345.4 & 1.34 \\
\hline 65 & 191.4 & 1.56 \\
\hline 85 & 0.7 & 2.83 \\
\hline
\end{tabular}

The gel melting is known to be related to the helix-coil transition as confirmed by the increases in chain mobility.

of the polymer initially packed as double helices aggregates (Table 4)

\section{CONCLUSION}

Red algae (Rhodophyta) are known as source of unique sulfated galactans, such as agar, also named agarose in absence of sulphated units. The wide practical uses of these polysaccharides are based on their ability to form strong gels in water or in $\mathrm{KCl}$ solutions.

In a first part of this work, the chemical structure was briefly described using ${ }^{1} \mathrm{H}$ NMR and gas chromatography after total hydrolysis. The extract from original algae named Gelidium sp (16 w \% on basis of the dried algae was recovered) was built up of the characteristic repeating disaccharide units found in agarose with a low yield in methyl substituents on the A unit.

In a second step, the rheological properties of the extract were studied: this Gelidium sp extract formed strong gels in water and in presence of $0.1 \mathrm{M} \mathrm{KCl}$. For this original agar the critical concentration for gelation was determined around $2 \mathrm{~g} / \mathrm{L}$. The influence of temperature characterized the thermoreversible gel with a large hysteresis at $10 \mathrm{~g} / \mathrm{L}$ and a melting temperature at $83{ }^{\circ} \mathrm{C}$ in the experimental conditions adopted.

These results demonstrated that this new algae collected along Madagascar coasts has a great potential for a future development.

\section{CONFLICTS OF INTEREST}

The authors confirm that this article content has no conflicts of interest.

\section{ACKNOWLEDGEMENTS}

The authors thank I.Jeacomime and L.Buon for their technical assistance with NMR and chromatography experiments. M. P. R. is grateful to CERMAV (CNRS) and CNRE (MESupRES) for giving her the opportunity to stay in CERMAV to perform this cooperative work, the AUF for the financial support, and the "Algues/CNRE" project, for samples collection.

\section{REFERENCES}

[1] Lewis, I.G.; Stanley, N.F.; Guist, G.G. In Algae and Human Affairs, Lembi, C.A.; Waaland, J.R., Eds. Cambridge University Press, New York, 1988; pp. 205-236.

[2] Rehm, B.H.A. Alginates: Biology and Applications. Microbiol. monogra., Vol. 13. Springer-Verlag, Berlin Heidelberg, 2009.
[3] Skjak-Braek, G.; Martinsen, A. Applications of some algal polysaccharides in biotechnology, In Seaweed Resources in Europe: Uses and Potential, Guiry, M.D.; Blunden, G.;Ed;. John Wiley \& Sons, 1991, pp. 219-256.

[4] Renn, D.W. Agar and agarose: indispensable partners in biotechnology. I\&EC Prod Res Develop, 1984, 23, 17-21.

[5] Araki, C.; Arai, K. Studies on the chemical constitution of agaragar. XVIII. Isolation of a new crystalline disaccharide by enzymatic hydrolysis of agar-agar. Bull. Chem. Soc. Jpn., 1956, 29, 339-345.

[6] Murano, E. Toffanin, R.; Zanetti, F.; Knutsen, S.H.; Paoletti, S.; Rizzo, R. Chemical and macromolecular characterisation of agar polymers from Gracilaria dura (C. Agardh) J. Agardh (Gracilariaceae, Rhodophyta). Carbohydr. Polym., 1992, 18, 171178.

[7] Andriamanantoanina, H.; Chambat, G.; Rinaudo, M. Fractionation of extracted Madagascan Gracilaria corticata palysaccharides: Structure and properties. Carbohydr. Polym., 2007, 68, 77-88.

[8] Hirase, S. Studies on the chemical constitution of agar-agar. XIX. Pyruvic acid as a constituent of agar-agar (Part 2). Isolation of a pyruvic acid-linking disaccharide derivative from the methanolysis products of agar. Bull. Chem. Soc . Jpn, 1957, 30, 70-75.

[9] Araki, C.; Hirase, S. Studies on the chemical constitution of agaragar. XXI. Re-investigation of methylated agarose of Gelidium amansii. Bull. Chem. Soc. Jpn, 1960 , 33, 291-295.

[10] Duckworth, M.; Yaphe, W. The structure of agar. Part I. Fractionation of a complex mixture of polysaccharides. Carbohydr. Res., 1971, 16, 189-197.

[11] Izumi, K. Chemical heterogeneity of the agar from Gracilaria verrucosa. J. Biochem., 1972, 72,135-140.

[12] Painter, T.J. Algal Polysaccharides. In The Polysaccharides, Vol. 2. Aspinall, G.O.; Ed.; Academic Press, New York, 1983, pp. 195285.

[13] Usov, A.I.; Yarotsky,S.V.; Shashkov, A.S. ${ }^{13}$ C-NMR spectroscopy of red algal galactans. Biopolymers, 1980, 19, 977-990.

[14] Duckworth, M.; Hong, K.C.; Yaphe, W. The agar polysaccharides of Gracilaria species. Carbohydr. Res., 1971, 18, 1-9.

[15] Rinaudo, M. Seaweed polysaccharides. In Comprehensive Glycoscience, Vol. 2: Polysaccharide Functional Properties. Kamerling, J. P.; Boons, G.-J; Lee, Y. C;. Suzuki, A ; Taniguchi, N.; Voragen, A.G.J.; Kamerling, J.P. Eds: Elsevier Science Technology: Oxford (UK), 2007, pp. 691-735.

[16] Guiseley, K.B. The relationship between methoxyl content and gelling temperature of agarose. Carbohydr. Res., 1970, 13, 247256.

[17] Tagawa ,S.; Kojima, Y. The alkali-treatment of the mucilage of Gracilaria verrucosa. Proc. Int. Seaweed Symp., 1972, 7, 447-450.

[18] Watase, M.; Nishinari, K. Rheological properties of agarose gels with different molecular weights. Rheol. Acta, 1983, 22, 580-587.

[19] Jimenez-Barbero, J.; Bouffar-Roupe, C.; Rochas, C.; Perez, S. Modeling studies of solvent effect on the conformational stability of agarobiose and neoagarobiose and their relationship to agarose. Int. J. Biol. Macromol., 1989, 11, 265-272.

[20] Kouwijver, M.; Pérez, S. Molecular modelling of agarose helices, leading to the prediction of crystalline allomorphs. Biopolymers, 1998, 46, 11-29.

[21] Welti, D.; Carrageenans. Part 12. The $300 \mathrm{MHz}$ proton magnetic resonance spectra of methyl $\beta$-D-galactopyranoside, methyl 3,6anhydro- $\alpha$-D-galactopyranoside, agarose, kappa-carrageenan and segments of iota-carrageenan and agarose sulphate. J. Chem. Res. (S), 1977, 312-313. 
[22] Izumi, K. Structural analysis of aga-type polysaccharides by NMR spectroscopy. Biochim. Biophys. Acta, 1973, 320, 311-317.

[23] Lahaye, M.; Rochas, C.; Yaphe, W. A new procedure for determining the heterogeneity of agar polymers in the cell walls of
Gracilaria spp. (Gracilariaceae, Rhodophyta). Carbohydr. Polym., 1986, 8, 285-301.

[24] Zhang, J; Rochas, C; Rinaudo M. Temperature dependence Of properties in gels of $\kappa$-carrageenan, agarose and their blends, Hua Dong Li Gong Da Xue/ ssJ. East China UST, 1990, 16(3), 322-328.

(C) Rahelivao et al.; Licensee Bentham Open.

This is an open access article licensed under the terms of the Creative Commons Attribution Non-Commercial License (http://creativecommons.org/licenses/ by-nc/3.0/) which permits unrestricted, non-commercial use, distribution and reproduction in any medium, provided the work is properly cited. . 